\title{
A CROSS- SECTIONAL STUDY ON CLINICAL PROFILE OF ALCOHOL INDUCED NEUROLOGICAL MANIFESTATIONS
}

\author{
Indira Priyadarsini Chandra1, Sreedevi Boppudi², S. Sai Charitha ${ }^{3}$, B. Vyshnavi ${ }^{4}$, N. Keerthi ${ }^{5}$ \\ ${ }_{1}^{1}$ Associate Professor, Department of General Medicine, ACSR Government Medical College, Nellore, Andhra Pradesh, India. \\ ${ }^{2}$ Associate Professor, Department of Community Medicine, ACSR Government Medical College, Nellore, Andhra Pradesh, India. \\ 3Pharmacy Student, Sri Padmavathi School of Pharmacy, Tirupati, Andhra Pradesh, India. \\ 4Pharmacy Student, Sri Padmavathi School of Pharmacy, Tirupati, Andhra Pradesh, India. \\ 5Pharmacy Student, Sri Padmavathi School of Pharmacy, Tirupati, Andhra Pradesh, India.
}

\section{ABSTRACT}

\section{BACKGROUND}

Alcohol is the most frequently consumed toxic substance in the world. Alcohol contributes to over 200 diseases and related health conditions, most notably alcohol dependence. Globally, alcohol misuse is the fifth leading risk factor for premature death and disability among people between the ages of 15 and 49 . WHO stated that in the age group 20-39 years, approximately 25 percent of the total deaths were attributable to alcoholism Acute- alcohol intoxication is associated with number of complications including accidents and domestic violence. During drinking periods and withdrawal, alcoholics commonly experience sleep disturbances like falling asleep and staying asleep (decreased total sleep time). Some neurological disorders related to long term alcoholism are predominantly due to inadequate nutrition (thiamine deficiency that causes Wernicke's encephalopathy), but others appear to involve the neurotoxicity of ethanol on brain (alcohol withdrawal syndrome and dementia) and peripheral nerves (alcoholic neuropathy and myopathy). ${ }^{1}$ We wanted to study the effect of alcohol on central and peripheral nervous system in alcohol abuse patients admitted to Sri Venkateswara Ramnarayan Ruia, Government General Hospital, Tirupati.

\section{METHODS}

A cross sectional study of neurological manifestations of alcohol was conducted in male patients who were admitted in the medical ward of SVRRGH, Tirupati from January 2017 to June 2017. Patients were subjected to predesigned and pretested questionnaire consisting of age, duration and quantity of alcohol intake, type of alcohol, sleep pattern, memory disturbance and clinical examination.

\section{RESULTS}

Mean age of the study subjects was 48.5 years. Sleep disturbance (Insomnia) was most commonly observed acute neurological manifestation in $90(60 \%)$ alcoholics out of 150 followed by withdrawal syndrome (46\%). Most common chronic neurological manifestation was peripheral neuropathy (28\%) followed by cerebellar degeneration (16.7\%). There was a statistically significant difference between age and cerebellar degeneration. ( $\mathrm{p}$ value $<0.5$ ).

\section{CONCLUSIONS}

A cross-sectional study of neurological manifestations of alcohol was conducted in male alcoholic patients admitted in medical ward of SVRRGH, Tirupati. Mean age of the study subjects was 48.5 years and half of them were dependent on brandy followed by country liquor. Most common acute neurological manifestation was sleep disturbance (insomnia) followed by withdrawal syndrome. Most common chronic neurological manifestation was peripheral neuropathy followed by cerebellar degeneration. There was a statistically significant difference between age and cerebellar degeneration. ( $\mathrm{p}$ value $<0.5$ ).

HOW TO CITE THIS ARTICLE: Chandra IP, Boppudi S, Charitha SS, et al. A cross- sectional study on clinical profile of alcohol induced neurological manifestations. J. Evolution Med. Dent. Sci. 2019;8(19):1555-1558, DOI: 10.14260/jemds/2019/345

\section{BACKGROUND \\ Alcohol is the most frequently consumed toxic substance in} the world. Alcoholism and alcohol abuse remain a significant health problem and represents the third leading cause of preventable death.

\section{Global Burden}

In 2012, 3.3 million deaths or 5.9 percent of all global deaths (7.6\% for men and $4.0 \%$ for women) were attributable to alcohol consumption. Alcohol contributes to over 200

'Financial or Other Competing Interest': None.

Submission 15-03-2019, Peer Review 30-04-2019,

Acceptance 06-05-2019, Published 13-05-2019.

Corresponding Author:

Dr. Sreedevi Boppudi,

Associate Professor, Department of Community Medicine,

ACSR Government Medical College, Nellore, Andhra Pradesh, India.

E-mail: sridevi.b.001@gmail.com

DOI: $10.14260 /$ jemds $/ 2019 / 345$ diseases and injury-related health conditions, most notably alcohol dependence, liver cirrhosis, cancers, and injuries. In 2012, 5.1\% of the burden of disease and injury worldwide (139 million disability-adjusted life-years) was attributable to alcohol consumption. Globally, alcohol misuse is the fifth leading risk factor for premature death and disability among people between the ages of 15 and 49 . WHO stated that in the age group 20-39 years, approximately 25 percent of the total deaths were attributable to alcoholism.

Some neurological disorders related to long term alcoholism are predominantly due to inadequate nutrition (The thiamine deficiency that causes Wernicke's encephalopathy), but others appear to involve the neurotoxicity of ethanol on brain (Alcohol withdrawal syndrome and dementia) and peripheral nerves (Alcoholic neuropathy and myopathy). ${ }^{1}$ Alcoholic "blackouts" can occur during heavy drinking and are characterized by hours of amnesia while awake. Immediate recall and long-term memory are normal but new events are forgotten, as in 
patients with transient global amnesia. When drinking is abruptly reduced or discontinued hyperexcitable withdrawal syndrome develops that is considered to be evidence of "physical dependence. Clinical features include tremulousness, disordered perceptions, convulsions, and delirium tremens ${ }^{2}$ Acute alcohol intoxication is associated with number of complications including accidents, domestic violence. During drinking periods and withdrawal, alcoholics commonly experience sleep disturbances like falling asleep and staying sleep (Decreased total sleep time).

Alcoholic polyneuropathy is characterized by axonal degeneration and demyelination. Although earlier clinical evidence suggested that inadequate nutrition was responsible, a specific vitamin deficiency has never been documented. Recent evidence suggests a direct neurotoxic effect of ethanol on peripheral nerves. 3

Alcohol dependence syndrome was more common in males as compared to females, this has a significant impact on the health and economic burden of the society. Alcohol dependence is a chronic disease associated with malnutrition, and a wide variety of CNS disorders. Wernicke and Korsakoff syndrome is the best neurological complication of alcoholism with thiamine deficiency.

\section{Aim of The Study}

To study the effects of alcohol on central and peripheral nervous system in alcohol abuse patients admitted to Sri Venkateswara Ramnarayan Ruia, Government General Hospital, Tirupati.

\section{Objectives of The Study}

1. To determine acute neurological manifestations of alcohol abuse.

2. To determine chronic neurological manifestations of alcohol abuse.

3. To determine socio demographic profile of study subjects.

\section{Inclusion Criteria}

Male patients aged between $20-80$ years who got admitted in medical ward.

\section{Exclusion Criteria}

1. Seriously ill and non-cooperative.

2. Those having diabetes.

\section{METHODS}

A cross sectional study of neurological manifestations of alcohol was conducted in male patients who were admitted in medical ward of SVRRGH, Tirupati from January 2017 to June 2017. Patients were subjected to predesigned and pretested questionnaire consists of age, duration and quantity of alcohol intake, type of alcohol, sleep pattern, memory disturbance and clinical examination

\section{Study Period}

Jan-June 2017.

\section{Study Setting}

SVRRGH, Tirupati

\section{Study Design}

Cross sectional

\section{Sample Size}

Sample size was taken based on the conveniences of the study.

\section{Statistical Analysis}

Data was entered in MS Excel and analyzed by using SPSS 17 version. Statistical tests like proportions and chi-square test were used.

\section{RESULTS}

Mean age of the study subjects was 48.5 years. Sleep disturbance (Insomnia) was most common observed acute neurological manifestation in $90(60 \%)$ alcoholics out of 150 followed by withdrawal syndrome (46\%).Most common chronic neurological manifestation was peripheral neuropathy $(28 \%)$ followed by cerebellar degeneration(16.7\%). There was a statistically significant difference between age and cerebellar degeneration. ( $p$ value $<0.5$ )

Sleep disturbance (insomnia) was most common observed acute neurological manifestation in $90(60 \%)$ alcoholics out of 150 followed by withdrawal syndrome (46\%).

Most common chronic neurological manifestation was peripheral neuropathy (28\%) followed by cerebellar degeneration (16.7\%).

Mean age of the study subjects was 48.5 years. The major duration of abstinence of alcohol is 5 to 12 months reported in $43 \%$ of study respondents. The major type of alcohol consumption is Brandy (50.7\%), followed by Country liquor in $26.7 \%$ etc.

\begin{tabular}{|c|c|c|}
\hline $\begin{array}{l}\text { Acute Neurological } \\
\text { Manifestations }\end{array}$ & Present (\%) & Absent (\%) \\
\hline Sleep disturbance (Insomnia) & $90(60)$ & $60(40)$ \\
\hline Withdrawal syndrome & $69(46)$ & $81(54)$ \\
\hline Hangover symptoms & $66(44)$ & $84(56)$ \\
\hline Blackout & $55(36.7)$ & $95(63.3)$ \\
\hline Sleep apnoea & $48(32)$ & $102(68)$ \\
\hline Dreams & $34(22.7)$ & $116(77.3)$ \\
\hline Seizures & $31(20.7)$ & $119(79.3)$ \\
\hline Impaired judgement & $19(12.7)$ & $131(87.3)$ \\
\hline Alcohol intoxication & $8(5.3)$ & $142(94.7)$ \\
\hline \multicolumn{3}{|c|}{$\begin{array}{l}\text { Table 1. Acute Neurological Manifestations of Alcoholics } \\
\qquad n=150\end{array}$} \\
\hline
\end{tabular}

\begin{tabular}{|c|c|c|}
\hline Chronic Manifestations & Present (\%) & Absent (\%) \\
\hline Peripheral neuropathy & $42(28)$ & $108(72)$ \\
\hline Cerebellar degeneration & $25(16.7)$ & 125 (83.3) \\
\hline Wernicke syndrome & $10(6.7)$ & 140 (93.3) \\
\hline Korsakoff psychosis & $2(1.3)$ & $148(98.7)$ \\
\hline \multicolumn{3}{|c|}{$\begin{array}{l}\text { Table 2. Chronic Neurological Manifestations of Alcoholics } \\
\qquad n=150\end{array}$} \\
\hline
\end{tabular}

\begin{tabular}{|c|c|}
\hline Social Factors & Percentage (\%) \\
\hline Age & $11(7.3)$ \\
$20-30$ & $26(17.3)$ \\
$30-40$ & $37(24.7)$ \\
$40-50$ & $43(28.7)$ \\
$50-60$ & $23(15.3)$ \\
$60-70$ & $10(7)$ \\
\hline
\end{tabular}




\begin{tabular}{|c|c|}
\hline $70-80$ & \\
\hline Abstinence of alcohol & $16(10.7)$ \\
$<5$ months & $65(43.3)$ \\
$5-12$ months & $20(13.3)$ \\
$12-18$ months & $6(4)$ \\
$18-24$ months & $24(16)$ \\
$24-30$ months & $5(3.3)$ \\
30-36 months & $14(9.3)$ \\
$>36$ months & $4(2.7)$ \\
Type of alcohol & $76(50.7)$ \\
Beer & $40(26.7)$ \\
Brandy & $3(2)$ \\
Country liquor & $27(18.0)$ \\
Rum & Whisky \\
\hline \multicolumn{2}{|c|}{ Table 3. Social Factors of Alcoholics $\boldsymbol{n}=150$} \\
\hline \multicolumn{2}{|c|}{}
\end{tabular}

\section{DISCUSSION}

In our study the mean age of the study subjects was 48.5 years. This finding was similar to Peng MC1, Chou WJ, Chen et $\mathrm{al}^{4}(47 \pm 1.3$ years). In the present study we observed sleep disturbance (insomnia) was most common acute neurological manifestation in $90(60 \%)$ alcoholics out of 150 . It is comparable to Caetano and colleagues $(1998)^{5}$ in their study they found that 67 percent of the men reported insomnia. Other studies like Aldrich 1998,6 Ehlers $2000^{7}$ found that Sleep problems are more common among alcoholics. Alcoholinduced blackouts observed in 55 (36.7\%) alcoholics out of 150 which was comparable to Reagan R. Wetherill, Ph.D. 1 et al, 8 in their study they reported blackouts in 50\% of alcoholics. In our study we found sleep apnoea in 48 (32\%) alcoholics. This finding was similar to Le Bon et al. 1997,9 Mamdani et al 1989,10 Tan et al $1985^{11}$ (29.3\%). Present study showed that 69 alcoholics(46\%) developed alcohol withdrawal syndrome, which was more when compared to
Peng MC, ${ }^{1}$ Chou WJ, Chen et al study ${ }^{4}(37 \%)$ because of local conditions and low socio-economic status. Alcohol induced seizures were observed in 31(20.7\%)alcoholics. This was similar to Peng MC, Chou WJ, Chen et $\mathrm{al}^{4}(18.1 \%)$ and Roger R Tuck et al ${ }^{12}(14 \%)$

In the present study we observed peripheral neuropathy in $42(28 \%)$ alcoholics. Though this was the most common finding in our study, but it was less when compared to Peng $\mathrm{MC}^{1}$, Chou WJ, Chen et al study ${ }^{4}$ (74.3\%), Roger R Tuck et al ${ }^{12}$ (34\%) because we excluded peripheral neuropathy due to nutritional and endocrinal disorders. Cerebellar degeneration was second most common finding in 25(16.7\%)alcoholics comparable to Peng MC, ${ }^{1}$ Chou WJ, Chen et al study ${ }^{4}(11.4 \%)$ and Roger $\mathrm{R}$ Tuck et al,12 reported in their study cerebellar degeneration was found to be $38 \%$. which was more when compared to our study, might be due to large sample size. Wernikes syndrome was observed in 10 (6.7\%) was less than Peng MC, ${ }^{1}$ Chou WJ, Chen et al study ${ }^{4}$ (15.2). Korsakoff's psychosis was the least common finding, observed in only 2 (1.3\%).

\section{CONCLUSIONS}

A cross-sectional study of neurological manifestations of alcohol was conducted in male alcoholic patients admitted in medical ward of SVRRGH, Tirupati. Mean age of the study subjects was 48.5 years and half of them were dependent on brandy followed by country liquor. Most common acute neurological manifestation was sleep disturbance (insomnia) followed by withdrawal syndrome. Most common chronic neurological manifestation was peripheral neuropathy followed by cerebellar degeneration. There was a statistically significant difference between age and cerebellar degeneration. ( $\mathrm{p}$ value $<0.5$ ).

\begin{tabular}{|c|c|c|c|c|c|c|c|c|}
\hline \multirow{2}{*}{$\begin{array}{c}\text { Neurologic } \\
\text { Manifestation }\end{array}$} & \multicolumn{8}{|c|}{ Age in Years } \\
\hline & 20-30 & $30-40$ & $40-50$ & $50-60$ & $60-70$ & 70-80 & Total & $\begin{array}{c}\text { Statistical } \\
\text { Significance } \\
\end{array}$ \\
\hline $\begin{array}{c}\text { Sleep disturbance } \\
\text { Yes } \\
\text { No }\end{array}$ & $\begin{array}{l}4 \\
7 \\
\end{array}$ & $\begin{array}{l}13 \\
13 \\
\end{array}$ & $\begin{array}{l}26 \\
11 \\
\end{array}$ & $\begin{array}{l}27 \\
16 \\
\end{array}$ & $\begin{array}{c}14 \\
9\end{array}$ & $\begin{array}{l}7 \\
3 \\
\end{array}$ & $\begin{array}{l}89(59 \%) \\
61(41 \%) \\
\end{array}$ & $\begin{array}{c}\mathrm{x} 2=7.084 \\
\mathrm{df}=5 \\
\mathrm{p}=0.313, \mathrm{NS}\end{array}$ \\
\hline $\begin{array}{l}\text { Withdrawal } \\
\text { syndrome } \\
\text { Yes } \\
\text { No }\end{array}$ & $\begin{array}{l}2 \\
9\end{array}$ & $\begin{array}{c}1 \\
25\end{array}$ & $\begin{array}{c}4 \\
23\end{array}$ & $\begin{array}{c}1 \\
42\end{array}$ & $\begin{array}{c}0 \\
23\end{array}$ & $\begin{array}{l}1 \\
9\end{array}$ & $\begin{array}{c}9(6 \%) \\
141(94 \%)\end{array}$ & $\begin{array}{c}x 2=7.605 \\
d f=5 \\
p=0.269, N S\end{array}$ \\
\hline $\begin{array}{c}\text { Peripheral } \\
\text { neuropathy } \\
\text { Yes } \\
\text { No } \\
\end{array}$ & $\begin{array}{c}1 \\
10 \\
\end{array}$ & $\begin{array}{c}3 \\
23 \\
\end{array}$ & $\begin{array}{l}13 \\
24 \\
\end{array}$ & $\begin{array}{l}12 \\
31 \\
\end{array}$ & $\begin{array}{c}8 \\
15 \\
\end{array}$ & $\begin{array}{l}5 \\
5 \\
\end{array}$ & $\begin{array}{c}42(28 \%) \\
108(72 \%)\end{array}$ & $\begin{array}{c}x 2=10.604 \\
d f=5 \\
p=0.099, N S\end{array}$ \\
\hline $\begin{array}{c}\text { Cerebellar } \\
\text { degeneration } \\
\text { Yes } \\
\text { No } \\
\end{array}$ & $\begin{array}{c}1 \\
10\end{array}$ & $\begin{array}{c}2 \\
24 \\
\end{array}$ & $\begin{array}{c}3 \\
34 \\
\end{array}$ & $\begin{array}{c}7 \\
36 \\
\end{array}$ & $\begin{array}{c}7 \\
16 \\
\end{array}$ & $\begin{array}{l}5 \\
5 \\
\end{array}$ & $\begin{array}{c}25(17 \%) \\
125(83 \%)\end{array}$ & $\begin{array}{c}x 2=17.057 \\
d f=5 \\
p=0.009, S\end{array}$ \\
\hline \multicolumn{9}{|c|}{ Table 4. Association Among neurological Manifestations and Age } \\
\hline Ther & s a stat & lly sign & t asso & on betw & age anc & ebellar & eneration. ( & $<0.5)$. \\
\hline
\end{tabular}




\section{REFERENCES}

[1] Diamond I, Messing RO. neurological effects of alcoholism. West J Med 1994;161(3):279-287.

[2] Victor M, Adams RD. The effect of alcohol on the nervous system. Res Publ Assoc Nerv Ment Dis 1953;32:526-73.

[3] Claus D, Eggers R, Engelhardt A, et al. Ethanol and polyneuropathy. Acta Neurol Scand 1985;72(3):312-6.

[4] Peng MC, Chou WJ, Chen SS. Neurological problems in chronic alcoholics. Gaoxiong Yi Xue Ke Xue Za Zhi 1991;7(8):404-12.

[5] Caetano R, Clark CL, Greenfield TK. Prevalence, trends, and incidence of alcohol withdrawal symptoms: analysis of general population and clinical samples. Alcohol Health Res World 1998;22(1):73-9.

[6] Aldrich M. Effects of alcohol on sleep. National Institute on Alcohol Abuse and Alcoholism Research Monograph Series. Vol. 33. Bethesda, MD: National Institutes of Health (NIH Publication No. 98-4163) 1998:281-300.

[7] Ehlers CL. Alcohol and sleep: National Institute on Alcohol Abuse and Alcoholism Research Monograph Series. Vol. 34. Bethesda, MD: National Institutes of Health 2000:417-33.
[8] Wetherill RR, Fromme K. Alcohol-induced blackouts: a review of recent clinical research with practical implications and recommendations for future studies Alcohol Clin Exp Res 2016;40(5):922-35.

[9] Le Bon O, Verbanck P, Hoffmann G, et al. Sleep in detoxified alcoholics: impairment of most standard sleep parameters and increased risk for sleep apnea, but not for myoclonias--a controlled study. J Stud Alcohol 1997;58(1):30-6.

[10] Mamdani M, Hollyfield R, Ravi RD, et al. Prevalence of sleep apnea among abstinent chronic alcoholic men (abstract). Sleep Research 1989;18:349.

[11] Tan ETH, Lambie DG, Johnson RH, et al. Sleep apnoea in alcoholic patients after withdrawal. Clinical Science 1985;69(6):655-61.

[12] Tuck RR, Jackson M. Social neurological and cognitive disorders in alcoholics. Med J Aust 1991;155(4):225-9. 